\title{
Modernidade: uma impressão
}

\author{
Modernity: an "impression" \\ Gustavo Silva Saldanha \\ Pesquisador adjunto do Instituto Brasileiro de Informação em Ciência e Tecnologia - IBICT. \\ Professor adjunto da Universidade Federal do Estado do Rio de Janeiro - UNIRIO. \\ E-mail: saldanhaquim@gmail.com
}

\section{Resumo}

Da Gramatologia de Derrida à Arqueologia dos Saberes de Foucault, um pensamento filosófico-bibliográfico se consolida, mas tem seu nascimento nas primeiras "aparições" da filosofia ocidental, nas disputas entre parmenídicos e heraclitianos, entre sofistas e socráticos, entre uma cultura clássica e o helenismo. Um certo metaforismo do livro, colaborador direto da construção conceitual de "modernas" concepções de mundo, desde os gregos, se apresenta à história do pensamento. O conceito de "gramatização" tem aqui papel preponderante: ele relaciona objetivamente as transformações do pensamento junto das transformações da linguagem. A proposta desta reflexão filosófica é discutir a relação ubíqua, em um longo decurso histórico, das conexões subjacentes entre uma teoria conhecimento e uma teoria bibliográfica, que "desemboca" atualmente nos discursos tecidos entre tecnologia e linguagem, os quais resultam, por sua vez, na centralidade do papel da Bibliografia, como gesto, arte, ciência. A inflexão histórica tem papel preponderante aqui não por conta da demarcação de uma historiografia das tecnologias da linguagem, mas na possibilidade de realização de suturas no tempo-espaço de afirmação de um ethos bibliográfico que está costurado na passagem das culturas nômades para uma racionalidade sedentária, dependente de memórias estáveis. Deste modo, de uma teoria do conhecimento como "transformação moderna" do pensamento anti-mitológico na Antiguidade (pré-século V antes de Cristo), às novas tecnologias da linguagem pós-1960, uma epistemologia prática, ou seja, uma teoria bibliográfica do conhecimento se estabelece lentamente, constituindo uma episteme distinta em paralelo à história do próprio projeto histórico do pensamento filosófico.

Palavras-chave: Modernidade. Livro. Impressão. Bibliografia. Teoria do conhecimento.

\begin{abstract}
From Derrida's Grammatology to Foucault's Archaeology of Knowledge, a philosophical-bibliographic it thought is consolidated, but has its birth in the first "appearances" of Western philosophy, in disputes between sophists and Socratics, between the classical culture and Hellenism. The purpose of this philosophical reflection is to discuss the ubiquitous relationship in a historical course of relations between theory of knowledge and bibliographic theory of knowledge, which currently leads the issue between technology and language, resulting, in turn, on the centrality of the role of Bibliography. The historical reflection plays an important role here not because of the demarcation of a history of language technologies, but the possibility of holding sutures in the statement of time-space of a bibliographic ethic that is sewn on the passage of the nomadic culture to a sedentary rationality, dependent on stable memories. Thus, from a theory of knowledge as "modern transformation" of the anti-mythological thought in antiquity, to the new technologies of post-1960 language, an epistemology, or a bibliographic theory of knowledge is established slowly, constituting a distinct episteme in parallel to the history of philosophical thought itself.
\end{abstract}

Keywords: Modernity. Book. Print. Bibliography. Theory of knowledge.

InCID: R. Ci. Inf. e Doc., Ribeirão Preto, v. 7, n. esp., p. 7-22, ago. 2016.

DOI: 10.11606/issn.2178-2075.v7iespp7-22 
Modernidade: uma impressão

\title{
Preâmbulos à pena da palavra escrita
}

\begin{abstract}
Ao falar do 'fim do livro' em curso, referia-me ao que certamente já se anunciava, e de que falamos esta noite, mas visava sobretudo ao modelo ontológicoenciclopédico ou neo-hegeliano do grande livro total, o livro do saber absoluto, que reúne em si, circularmente, sua própria dimensão infinita. (DERRIDA, 2014, p. 30)
\end{abstract}

A proposta desta reflexão filosófica é discutir a relação ubíqua, em um decurso histórico de vasta duração, das interposições de uma teoria do conhecimento e uma teoria bibliográfica, que desembocam atualmente nos discursos tecidos entre tecnologia e linguagem, estes que resultam, por sua vez, na centralidade do papel da Bibliografia, como gesto, arte, ciência. A inflexão histórica tem papel preponderante aqui não por conta da demarcação de uma historiografia das tecnologias da linguagem, mas na possibilidade de realização de suturas no tempo-espaço de afirmação de um ethos bibliográfico que está costurado na passagem das culturas nômades para uma racionalidade sedentária, dependente de memórias estáveis.

Neste sentido, faz-se aqui uso da noção de "história" para constituir uma relação entre os elementos tecidos em sociedades antigas, medievais e modernas que nos permitem uma reflexão filosófica (e, deste modo, inicialmente não histórica) sob como a relação aqui iluminada, entre tecnologia e linguagem, tem fundamentação direta sob os mais diferentes processos do que nós, "modernos", tão popularmente chamamos, modernismos, modernidade, modernização. Especificamente, sob o ponto de vista da filosofia da linguagem, em diálogo pontual com Auroux (2009), percebemos que os princípios de gramatização resultam em importantíssimas inovações no sentido técnico e filosófico, ou seja, a linguagem se relaciona diretamente com as transformações tecnológicas e aquelas de fundo filosófico (novos conceitos, novas abordagens, novos métodos). A "modernização" do processo de construção da escrita nas sociedades antigas, por exemplo, representa, na visão aurouxiana, uma espécie de objetivação e de estabelecimento da condição da representação metalinguística, pressupondo o discurso sobre dado elemento a partir de sua condição mimética, aspecto fundamental para toda a elaboração histórica do pensamento ocidental, em suas discussões entre observador e observado, sujeito e objeto.

A ideia de Modernidade, em maiúscula, como a ideia daquilo que se apresenta como moderno, traz consigo uma lista de produtos e processos intimamente correlacionados. Podemos incluir neste elenco inovação, ruptura, novos artefatos, novas técnicas, novos 


\section{Gustavo Silva Saldanha}

hábitos, novas ideias. Em todos os contextos, o ato de modernizar pressupõe uma mudança de estado, outra modalidade de apropriação do espaço e do tempo. É esta a questão central do entrelaçamento de tecnologia e linguagem, articulado, em nossa visão, pela noção de gramatização, que pode ser desdobrado, nesta reflexão, em pelo menos três grandes dimensões: tecnologias da linguagem (propriamente ditas), linguagem como tecnologia e, por fim, a linguagem (simultaneamente) como teoria, método e ferramenta para construção de tecnologias.

Estas reflexões são advindas dos estudos sobre a construção histórica do pensamento informacional, mais especificamente, a busca por uma compreensão, um modo de interpretar as especificidades da teoria do conhecimento que se estabelece dentro de nosso pensamento. Do mesmo modo, aproxima-se objetivamente das relações entre filosofia da linguagem e a tessitura desta teoria do conhecimento, ou seja, de nossas formas de agir e pensar quando nos deparamos com objetos e processos como escrita, livros, documento, informação, classificação, representação, preservação. Dois projetos específicos respondem por estas abordagens, sendo respectivamente, "Epistemologia histórica do pensamento biblioteconômico-informacional: linguagem, instituições, artefatos e intersubjetividades" e "Trilhar o trivium: a filosofia da Ciência da Informação na tradição filosófica da linguagem". O primeiro tenciona os pressupostos "naturalizados" de nossa construção epistemológicohistórica, a partir da revisitação aos elementos sócio epistêmicos de nossa fundamentação. O segundo busca compreender nas artes liberais da gramática, da retórica e da lógica o fio condutor de sustentação filosófica de uma pretensa teoria geral de nosso campo (hoje predicado como informacional) e de suas múltiplas abordagens aplicadas. 
Modernidade: uma impressão

\title{
Achegas ao dilema filosófico-bibliográfico: a teoria do conhecimento sob a tábula rasa ou a tábula rasa da teoria do conhecimento
}

\begin{abstract}
O retorno que os antropólogos promoveram às civilizações sem livro, mas não sem escrita, os numerosos estudos realizados no campo da História do Livro entre os séculos XVI e XVII demonstram que o livro impresso provocou um verdadeiro trauma no conhecimento. (MELOT, 2012, p. 139)
\end{abstract}

As dimensões anteriormente colocadas, a saber, tecnologias da linguagem, linguagem como tecnologia e, por fim, a linguagem (simultaneamente) como teoria, método e ferramenta para construção de tecnologias, são fruto de um longo processo reflexivo que tem aparentemente a Modernidade, em maiúscula, como sua progenitora (a questão do livro como uma questão pós-gutenbergiana). No entanto, é através de inflexões filosóficas pontuais, desde a Antiguidade, que podemos repensá-la no presente. A primeira dimensão pode ser reconhecida como aquela mais genericamente abordada no contexto atual. Trata-se de um modo de perceber e listar o conjunto abordagens e instrumentos projetados para o desenvolvimento e-ou usados deliberadamente em tais dispositivos para dispor ou dar fluxo a dados linguísticos, verbais ou a-verbais. Aglutinam-se aqui os sistemas em linha contemporâneos de acesso à informação, mas também livros, aparelhos radiofônicos, transmissores de dados de imagem em movimento, por exemplo, em geral reunidos sob a noção de "tecnologias da informação e da comunicação" - o que Auroux (1998, 2009) caracteriza como terceira grande revolução técnico-linguística.

A segunda dimensão, a linguagem como tecnologia, visa ao modo de interpretação das articulações fundacionais de nossos meios de comunicação como fonte a priori do desenvolvimento das tecnologias ditas da linguagem, como aquelas mencionadas acima. Trata-se de perceber a própria linguagem em sua atividade, em sua "práxis" na coletividade dos indivíduos, como a tecnologia "em si", como um desdobramento da técnica e uma reflexão ativa sobre a própria arte, sobre o próprio fazer da linguagem. Isto significa dizer, em síntese, que, resguardadas todas as diferenças e singularidades de cada tecnologia da linguagem, todas elas "são" parte desta categoria a priori (porém, ressalta-se, uma anterioridade não metafísica, mas linguística, ou seja, coletivamente tecida a partir de grupos de indivíduos) na medida em que são "filhas" de uma tecnologia já dada, a linguagem, capaz de gerar uma miríade de potencialidades e atualizações no mundo da linguagem. Deste modo, o movimento, não demarcável no tempo histórico, mas possível de uma "sugestão" na dedução filosófica, da oralidade, assim como o da escrita, são, antes de técnica, frutos de uma 
certa "tecnologia sócio cognitiva" que nos permitiu a imagem desenvolvida sob novos arranjos destas dinâmicas técnicas sócio materiais, ou seja, escrita e oralidade, podendo, para tal, refletir, como um logos sobre a técnica, ou ainda, racionalidade, discurso sobre ela, a técnica.

É nesta última margem que podemos situar, como desdobramento reflexivo, a dimensão derradeira: a linguagem (simultaneamente) como teoria, método e ferramenta, fonte de desenvolvimento e crítica das próprias tecnologias da linguagem. Em certa medida esta discussão está presente em toda a querela da linguagem nos diálogos platônicos, principalmente no Fedro, no Górgias, no Sofista e no Protágoras. Trata-se de adentrarmos no jogo que postula a linguagem (no sentido socrático-platônico) não como fonte da filosofia, não como possibilidade de verdade, todavia, ao mesmo tempo, de reconsiderá-la todas as vezes em que se coloca o discurso sobre o ser em questão. Em outros termos, a filosofia não pode sucumbir à linguagem, pois esta, quando muito, é uma ferramenta, e, enquanto tal, assim deve ser tomada. Porém, na ausência completa de linguagem, em que condição se expressa a filosofia, sob quais estacas se instala a possibilidade de verdade tecida entre os homens?

Em nossa visão, a partir do sentido aurouxiano, as dimensões apresentadas e seus dilemas podem ser traduzidos e discutidos com vistas a uma compreensão tanto filosófica quanto prática a partir do conceito de gramatização. Ele indica o conjunto de processos e produtos, de interações e apropriações, resultantes de complexas padronizações linguísticas. Na síntese de Auroux (2009, p. 65), trata-se de todo "processo que conduz a descrever e instrumentar uma língua na base de duas tecnologias, que são ainda hoje os pilares de nosso saber metalinguístico: a gramática e o dicionário". Em um sentido de sumarização, teríamos três grandes revoluções técnico-linguísticas:

- A invenção da escrita - primeira estabilidade, que se multiplica com a invenção da prensa;

- A gramatização das línguas do mundo - segunda estabilidade (políticas de línguas do mundo, políticas linguísticas nacionais e de alfabetização);

- O tratamento eletrônico da informação (que utiliza e potencializa as revoluções anteriores) (AUROUX, 1998, p. 289, grifo nosso)

Estas "revoluções da estabilidade", que aqui gostaríamos de tratar também como "modernizações", alteram sensivelmente, na abordagem aurouxiana, a organização das sociedades humanas. No âmbito da segunda revolução técnico-linguística, percebe-se, por exemplo, a constituição de uma "rede homogênea de comunicação centrada inicialmente na 
Modernidade: uma impressão

Europa” (AUROUX, 2009, p. 35), elemento político tão enormemente importante para compreender a noção "moderna" de Modernidade.

Mais do que isto, tais revoluções colocam em um só plano analítico a relação entre teoria do conhecimento e uma teoria bibliográfica do conhecimento, pois subjazem no cerne das relações extremamente sobrepostas da linguagem, da tecnologia e do saber. Sob o ponto de vista da gramatização, como aponta Auroux (2009, p. 36), “A mutação das ciências da natureza", com Copérnico, Galileu e Descartes, ou seja, a condução da definição de uma teoria do conhecimento para a Modernidade, "é com certeza praticamente contemporânea, em suas origens, à virada decisiva que afetou o processo que descrevemos, mas suas consequências práticas (a industrialização) são mais tardias”. Se as ciências da natureza chegam primeiramente "à grande síntese teórica" (centralmente com Newton) e influenciarão, posteriormente, as ciências humanas, na visão aurouxiana estas últimas, os estudos do homem, são amplamente anteriores em sua "constituição teórica e em suas realizações tecnológicas". Em outras palavras, não existiria, sem uma segunda revolução técnicolinguística, o acontecimento das ciências modernas, nem suas repercussões sociais, ou seja, uma teoria do conhecimento que sustenta a noção de Modernidade está diretamente atrelada às "modernizações" da linguagem.

Repensando as dimensões que colocam tecnologia e linguagem no cerne das "modernizações" do pensamento, podemos remontar efeitos de uma teoria do conhecimento que se articulam decisivamente com a questão de uma teoria bibliográfica do conhecimento. Uma parte da filosofia, podemos afirmar tendo em vista o Fedro de Platão e a Retórica de Aristóteles, tende a correlacionar objetivamente o conhecimento com a linguagem, seja para tratar de suas condições, seja para apontar seus riscos e suas aporias. Especificamente, uma noção que se tornou cara à construção de diferentes modos de conceber o conhecimento pode ser encontrada em diferentes modos na filosofia e obedece à ordem dos discursos que aproximam linguagem e verdade. Trata-se da conhecida tábula rasa e sua presença em manifestações filosóficas que buscam uma epistemologia geral do humano para o transcendente ou para o sensível. A noção evoca não apenas as relações contemporâneas sobre o mundo da escrita, mas também os pressupostos de uma "filosofia da linguagem" entrelaçada a uma "teoria do conhecimento", no centro do qual, em nossa visão, gravita uma teoria bibliográfica, ou, como temos chamado, uma teoria bibliográfica do conhecimento. 
Por tábula rasa reconhecemos, em geral, a condição de nossa alma no momento anterior à aquisição de conhecimentos, significação comum na Antiguidade. Tal metáfora nasce justamente da comparação entre os processos do conhecer e do escrever sobre tábulas cobertas por cera no mundo antigo. A metáfora estaria já em Ésquilo, ou seja, em seu Prometeu, na relação objetiva entre condição humana e sua cultura. Em seu Teeteto, Platão compara a alma a um conjunto de elementos de cera onde não se encontra nada inserido, nada escrito. Do mesmo modo, Aristóteles, no De Anima, aproxima o intelecto a uma tábua vazia de inscrições. Dos estoicos aos medievais, chegando à Locke e Leibniz, a expressão foi adotada, ganhando diferentes sentidos de acordo com a corrente filosófica, sendo seu uso na Modernidade vinculado à afirmação da construção objetiva do conhecimento no mundo empírico, anti-inatista. (ABBAGNANO, 2000)

Percebemos que esta noção, cara aos discursos sobre o ser, mas afastada quando das discussões sobre linguagem e ser (exemplo, no Górgias e no Fedro platônicos), demonstra os princípios contraditórios e as margens de discussão que a gramatização e os processos e os produtos bibliográficos "impõem" ao pensamento de um modo geral. A tábula rasa é simultaneamente um modo de demonstrar o acontecimento de uma teoria do conhecimento, mas seria apenas isto? Seus usos reconhecidos ou despercebidos na Modernidade tardia, nos estudos informacionais, sugerem o mero acaso de uma figura de linguagem? As práticas modernas de relacionar a prática de aquisição de conhecimento com a prática da leitura, os entrecruzamentos entre mundo bibliográfico (bibliotecas, por exemplo) e conhecimento seriam simples abstrações de uma antiga transcendental ideia de verdade?

\section{- O grafito do ser: a verdade talhada na carne do tempo histórico}

Sob ou sobre a noção da tábula rasa, o mefatorismo do escrito se multiplica. O trabalho de Ernst Curtius sobre o "livro como símbolo" demonstra a longa tradição de pensamento, que costura conhecimento, teoria do conhecimento e o artefato bibliográfico, a ponto de, em dadas ocasiões, as diferenças entre tais elementos se perderem. Curtius (1996, p. 377) demonstra que o "emprego da escritura e do livro na linguagem figurada ocorre em todas as épocas da literatura universal, mas com diferenças características, condicionadas pela marcha da cultura geral". Nem fatores políticos, nem teológicos, nem epistemológicos propriamente ditos, caso tais divisões possam ser claramente estabelecidas no decurso histórico do homem, anunciam o apagamento das relações indicadas acima: Antiguidade, 
Modernidade: uma impressão

Medievo e Modernidade guardam fundamentações aproximadas, passando do livro sagrado (transcendente) ao livro da natureza, chegando ao livro como produto e propulsão do social após o século XIX.

Nola (2000) demonstra que, partindo de diferentes inflexões sobre o nascimento da prática de escrita, o que resultará da construção do livro, partícipes da arqueologia indiciária de elementos etimológicos (a pragmática inaugural de denominação das coisas conforme seu uso), podemos reconhecer a identidade da noção do "incisar" nesta origem. Posteriormente, noções como "traçar sinais" em diferentes idiomas, scribere (imprimir, em latim), writan (talhar, em inglês), rîzan (incisar, em alemão), por exemplo, atestam a relação direta entre o escrever e o traçar grafitos.

Na Grécia antiga, a noção de livro em seu caráter sagrado e a expressão da escritura recebem ainda pouca representação simbólica. Segundo Curtius (1996, p. 377), o “emprego do sentido figurado da escritura e do livro é desconhecido na poesia grega desde o início. Nem Homero nem Hesíodo o conhecem". Esta "negligência" está justificada na visão platônica apresentada no Fedro - visão esta que, em certa medida, já inaugura as condições para o simbolismo inerente ao livro. No entanto, como já discutido, a noção de tábula rasa, por sua vez, antecipa a pragmática do livro, e, ao mesmo tempo, a inaugura.

No helenismo e, especificamente, em Alexandria, o "livro", ou, apenas, o registro da produção dos saberes do homem, ganha as camadas infinitas de simbolismo. "Agora a criação poética transformou-se em laborioso trabalho noturno de escritório [...] Os epigramas para bibliotecas e seus tesouros tornam-se exercícios poéticos”. (CURTIUS, 1996, p. 379). Este é, no sentido aurouxiano, o grande momento gramatical inaugural, a atmosfera que faz nascer a noção de gramática como conhecemos (AUROUX, 2009, p. 29). O livro passa a ser tanto a metáfora ideal como a matéria mimetizada do pensamento humano em sua excelência.

No contexto da Biblioteca de Alexandria, o livro "reduz-se ao domínio da filologia e da biblioteconomia, da caligrafia, da bibliofilia e da bibliomania” (CURTIUS, 1996, p. 381). Porém, com Plotino, no século terceiro, o livro é visto já tanto como "efeito literário" - donde podemos retirar o elo retórico-bibliológico por trás de seu simbolismo - como elemento destinado a "estimular o conhecimento" - donde podemos retirar a raiz filológicobibliológica. (CURTIUS, 1996, p. 381).

O metaforismo bibliológico puro - o livro como metáfora do mundo e do homem - é, deste modo, construído a partir da Antiguidade, passando pelo Medievo (na Cristandade, onde 
o livro atinge sua "consagração máxima") (CURTIUS, 1996, p. 384) e chega até a Modernidade, onde a noção de "livro" ganha o significado de liberdade de expressão (vide o papel da cultura impressa na Reforma Protestante), a partir das máquinas miméticas, como a prensa, que permitem sua multiplicação ao inabarcável. Do Livro da Vida, do Antigo Testamento - o Livro de Deus - ao Livro da Natureza - ou do Mundo -, consagrado pelo humanismo da Renascença, ao Livro do Homem, da Modernidade científica, da democracia, percorremos um período extenso de reinvenção (ou reconsagração) da noção de "livro", que traz consigo a caixa de ferramentas sub-conceituais da tábula rasa e de todos os gestos bibliográficos a ela inerentes, como escrever, ler, ouvir, falar. Esta “caixa de ferramentas" é formalmente a base de diferentes abordagens filosóficas no século XX, passando por nomes como Wittgenstein, Derrida, Foucault e chegando até Habermas. Ela está, também, na base de tudo aquilo que tratamos quando enunciamos a chamada "virada linguística" da Filosofia. Por fim, a caixa de ferramentas de uma teoria bibliográfica do conhecimento, lida hoje, recoloca em questão a preponderância histórica da gramatização, e as relações entre uma filosofia da linguagem na Antiguidade e suas possibilidades de "dizer o ser" e estas abordagens contemporâneas.

\section{- O “dito ser": notas sobre os primórdios de uma certa "história tecnopolítica da escrita"}

Da metáfora tomada como afastamento ou simples alegoria para uma teoria do conhecimento na Grécia Antiga ao ponto de inflexão da metáfora como esclarecimento filosófico pode-se compreender uma relação fundacional entre o discurso filosófico grego sobre o conhecimento e o discurso sobre a linguagem, incluindo o mundo bibliográfico como desdobramento desta. De lá aos dias atuais, a questão do conhecimento adquire relações objetivas com o mundo da linguagem e suas teses. Todo o projeto gramatológico, por exemplo, de Jacques Derrida no século XX aponta para a questão do livro como espécie de "memorial" tanto abstrato quanto sensível para a querela entre conhecimento e linguagem:

Ora, o que se passa, o que se anuncia como a forma mesma do por-vir do livro, ainda como livro, é, por um lado, para além do fechamento do livro, a irrupção, a deslocação, a disjunção, a disseminação sem reunião possível, a dispersão irreversível desse códice total (não seu desaparecimento, mas sua marginalização ou sua secundarização, de acordo com modos a que seria preciso retornar), mas simultaneamente, por outro lado, o reinvestimento constante do projeto livresco, do livro do mundo ou do livro mundial, do livro absoluto (por isso, esse fim do livro, eu o descrevia também como interminável, sem fim, o novo espaço da escrita e da 
Modernidade: uma impressão

leitura da escrita eletrônica, que viaja a toda velocidade de um ponto a outro do mundo, e que liga, para além das fronteiras e dos direitos, não apenas os cidadãos do mundo na rede universal de uma universitas potencial, de uma enciclopédia móvel e transparente, mas qualquer leitor como escritor possível ou virtual, etc. Isso relança um desejo, o mesmo desejo. Isso re-induz a tentação de considerar que a rede mundial da $W W W$ é a figura como o Livro ubíquo enfim reconstituído, o livro de Deus, o grande livro da Natureza, ou o Livro-Mundo seu sonho onto-teológico enfim realizado, muito embora ele repita o fim como por-vir. (DERRIDA, 2014, p. 30-31)

Na visão de Cassin (2005), a própria relação entre o nomos e o eikos, guarda a luta entre a aletheia e a physis, remontando a antiga questão parmenídica entre ser e não-ser. Quando a linguagem se estabelece como força direta de interpretação da teoria do conhecimento, ela subverte, já na Antiguidade, com Górgias e Protágoras, por exemplo, o $a$ priorismo da verdade e seu afastamento da physis.

A identidade dos indivíduos e das condutas se encontra assim difratada, perfeita
encenação do fato de que a 'verdade' sempre é segunda. Assim como o papiro
desdobra a imediatidade insuperável do nômico, face à qual a natureza não é mais do
que secundariamente primeira [...]. De um lado, então, o eikos, bem como o nomos,
são pura e simplesmente - quer dizer, magistralmente - o produto de um discurso
que consegue obter o consentimento para aquilo que ele apresenta, construindo,
assim, o espaço público. Por outro lado, a aletheia não existe mais do que a physis:
lógica ou física, elas só podem aparecer como um vácuo, uma escapada ou uma
escapatória, um secreto, do qual, por definição, nenhuma prova pública jamais será
dada definitivamente. (CASSIN, 2005, p. 73)

É neste sentido que, simultaneamente, o "nascimento" da filosofia no Ocidente a partir do ponto de vista historiográfico da presença de Tales, Parmênides e Sócrates, por exemplo, se estabelece vinculado à unidade do ser, como também se apresenta absolutamente mergulhada nos modos sobre como "dizer o ser" e, mais ainda, na questão do "ser" enquanto um produto do dizer, ocorrência esta presente nas argumentações de Platão e Aristóteles, como de Protágoras e Górgias.

A posição sofística [...] se caracteriza por uma 'ausência de distância', uma 'aderência total' entre 'a palavra' e 'o ser'. O risco inerente a essas metáforas é o de ter de estabelecer duas esferas distintas - a linguagem e o ser - para identificá-las. Elas são adequadas ao extremismo sofístico, caso se afirme que existe uma só esfera, a da linguagem, que produz um efeito, o ser. (CASSIN, 2005, p. 97)

A posição sofística, pontualmente, fundamenta uma co-constituição "substancial" entre "ser" e "dizer", entre verdade e linguagem, como se a metáfora da tábula rasa, antes de dizer pelo outro o fato linguístico que nos interessa, o diz na objetividade mais direta da definição conceitual: antes de colocar o registro como o distanciamento, a "máquina" da linguagem é a exata possibilidade da verdade "acontecer" entre os homens, sua margem de falha, de falsificação também, é certo, mas sua condição a priori e a posteriori aqui se estabelece. Nas palavras de Derrida (2014, p. 13), poderíamos dizer que existe aqui uma 
espécie de profunda ligação, “[...] o pensamento de um traço-de-união visível ou invisível entre o papel e a máquina”, por extensão, desde à Antiguidade, entre alma e mundo.

Esta relação, em uma leitura contemporânea de seu "passado" filosófico, Derrida (2014, p. 28) a chamará uma certa "história tecnopolítica da escrita", base de todo o seu projeto de mais de três décadas de construção de uma episteme, a qual chamou Gramatologia. Tal ciência que busca um "traço inaugural", o fim das dicotomias entre filosofias da presença (as filosofias do ser parmenídico) e as filosofias da ausência (filosofias da mediação “tecnolinguística", da pressuposição de forças não espirituais no mundo da physis) encontra no pensamento bibliográfico sua nascente, seu curso, e sua foz: uma teoria do conhecimento tecida sobre o objeto livro (escrita, documento, informação), incluindo a própria atividade reflexiva gramatológica derridiana, sustenta-se no "estranho" (para a filosofia inaugural dos gregos) relacionamento íntimo entre o conhecimento e a tábula rasa, para além de um modo de explicar esta condição.

Faz-se necessário lembrar que o conjunto de práticas "modernas" de fundo bibliográfico, tratadas por Derrida (2008) em sua Gramatologia como "práticas de informação", são tomadas como objeto crítico para pensar, na revisão gramatológica de uma teoria do conhecimento que atravessa o mundo antigo e chega à Modernidade tardia, a disputa entre o fonocentrismo (centralidade epistemológica da oralidade) contra uma teoria epistemológica da ausência, do dado mediado, da escritura, da exterioridade - ou, simplesmente, do livro. A ideia, pois, do "fim do livro", para um pensamento gramatológico, que recoloca, em nossa visão, toda a profundidade da noção de gramaticalização sob outra reflexão, é central para uma teoria do conhecimento, pois, em certa medida, esta última se estabelece, desde a tábula rasa, em uma relação objetiva com esta abstração (a reflexão sobre como adquirimos conhecimento) e-ou com sua manifestação sensível (a expressão materializada de todo e qualquer gesto bibliográfico).

Todo o neoplatonismo da Cristandade impõe, de certo modo, seja de maneira equívoca, seja de modo esclarecedor, a intensidade destas relações que coloca como "moderno", como transformador, exatamente o espectro da relação entre a empiria da incisão do mundo escrito e a verdade (sendo sua metáfora carnal a Sagrada Escritura), condição esta que a própria filosofia do ser, em certa medida, adotou, ainda que apenas para ilustrar o modo como o conhecimento chega até nossa condição humana de conhecedores sob a noção de tábula rasa.

InCID: R. Ci. Inf. e Doc., Ribeirão Preto, v. 7, n. esp., p. 7-22, ago. 2016. 
Modernidade: uma impressão

\section{Deus-Livre: a extensão maquínica do sagrado na medida do livro}

Os raros fragmentos de códices que chegaram até nós desde os primeiros séculos são, em sua maior parte, objetos cristãos. (MELLOT, 2012, p. 27)

Se tomarmos apenas a questão do sagrado sob o ponto de inflexão bibliográfico, notamos a construção de um certo "livro dissimulado" do neoplatonismo: Deus se embaralha com o códice; e o códice se torna um Deus-máquina, capaz de "globalizar-se" a partir de uma técnica impressionante do logos. "Antecipando: Deus é impensável sem a escrita essencialmente e sem a roda secundariamente, as quais reduzem, em vários graus, a dependência do homem em relação ao espaço (a roda) e ao tempo natural (a escrita)." (DEBRAY, 2004, p. 38). A curiosa (para os gregos, principalmente) filosofia cristã que prega a condição de "impressão" de Deus, ou seja, o filho de Deus é também sensível, não estando em uma condição transcendental em si, mas atualizado em carne e osso, esta filosofia estabelece a velha dificuldade de separação absoluta entre o real e o mundo sensível, a substância e seus acidentes, o verbo e seus predicados.

Esta condição acima pode ser tomada como mais "exótica" ainda quando apontamos para a condição do livro na filosofia cristã, ou da Sagrada Escritura como parte da fundamentação de uma cosmologia e de um logos sumário manifestado por Deus.

\footnotetext{
O homem descende do símio, mas Deus descende do signo e os signos têm uma longa história. A tecnogênese da transcendência é um momento a se restituir na tecnogênese do homem, processo sempre em curso diante dos nossos olhos, e cujos primórdios remontam aos primeiros instrumentos talhados bifacialmente, ou seja, ao acheuliano antigo, na África, há 1,4 milhão de anos (700 mil anos na França). Esse momento, a que podemos chamar de miraculoso, é de uma evolução espantosa, pois casou o nomadismo pastoril com a escrita alfabética. (DEBRAY, 2004, p. 39)
}

A "revolução técnico-linguística" manifestada acima por Debray (2004) reafirma a tensão entre tecnologia, linguagem e conhecimento manifestada pela filosofia aurouxiana. $\mathrm{Na}$ mesma linha de reflexão, Melot (2012) demonstra como a Igreja é fundamentalmente uma Igreja virtual, na medida em que se estabelece nesta certa tecnogênese debrayana ou em um profundo movimento tecnológico "modernizante" de gramatização: se a cultura é do claustro, mesmo no Medievo, o códice é "mendicante", o livro viaja, e a potencialidade de sua condição de meio é intangível. O códice torna-se, na visão melotiana, muito mais do que um ato de representação: trata-se de um gesto bibliográfico que pressupõe mutuamente uma forma de pensamento e um modelo de sociedade. Assim, "A escrita dos textos sagrados se impõe apenas no momento em que a doutrina se quer expansionista e se endereça a comunidades distantes, de cultura e de línguas diversas”. (MELOT, 2002, p. 34)

InCID: R. Ci. Inf. e Doc., Ribeirão Preto, v. 7, n. esp., p. 7-22, ago. 2016. 


\section{Gustavo Silva Saldanha}

Com Derrida (2014) percebemos que o uso do Deus-máquina é, controversamente, uma das bases para a fundamentação da técnico-liberdade da era moderna, das instituições de livre expressão, sempre confundidas como casas da liberdade de impressão. Exprimir-se e imprimir-se quase que se equivalem nessa longa história da costura entre teoria do conhecimento e conhecimento bibliográfico, uma longa história da incisão.

\footnotetext{
Tantas instituições (bem nacionais ou já internacionais, quando não universais), consagradas à máquina e ao papel, cada uma ordenada por um ritmo próprio, pela temporalidade original de sua sobrevivência.

Tantas instituições impondo (verifica-se isso na experiência da escrita e da leitura) suas normas, suas regras do jogo, a memória ou o fantasma de sua experiência, a autoridade de sua suposta competência.

Tantas instituições cujo nome, a cada vez, e apenas o título (por si só já algo enorme) mereceriam apenas elas mais de uma obra, livresca ou não. (DERRIDA, 2014, p. 14)
}

Em outras palavras, agora tomando também o ponto de vista cassiniano sobre o logos, os elementos centrais (ou grande parte deles) da democracia moderna repousam no mundo logológico grego e na segunda sofística dentro do Helenismo sob a égide romana. "O retorno retórico da sofística se dá por razões latinas: a coisa pública a ser abarcada pelo oradorcidadão, e essa relação com o político é, com razão, reconhecida como um patrimônio da sofística grega" (CASSIN, 2005, p. 186).

A síntese moderna desta questão, que atravessa o metaforismo do livro presente em Curtius, encontra novamente a visão de Derrida (2014) como objetiva: o livro, ressacralizado, refetichizado, vai da escrita fonética aos modos de impressão e reprodução, provocando um acúmulo de rupturas sócio políticas, partícipe que é, tal livro (forma, matéria, símbolo), ao mesmo tempo, da transcendentalização e da sacralização, como também da secularização e da democratização. 
Modernidade: uma impressão

\section{Outras Impressões: outras modernidades}

É que as margens de um livro jamais são nítidas nem rigorosamente determinadas: além do título, das primeiras linhas e da forma que lhe dá autonomia, ele está preso a um sistema de remissões a outros livros, outros textos, outras frases, nó em uma rede. (FOUCAULT, 2010, p. 27)

Diversas são as discussões que apontam para a mutação bibliográfica e as transformações do mundo moderno, como relacionadas em termos historiográficos na Modernidade por Burke (2002). Em outras palavras, a pergunta, afinal, o que é o "moderno" e o que é a "Modernidade", não pode ser respondida sem o questionamento sobre quais os impactos da produção bibliográfica pós-gutenbergiana no mundo das ideias: Reforma Protestante, Contrarreforma, Enciclopedismo, Revolução Francesa, Revolução Industrial, quantas seriam, de fato, as "institucionalidades modernas" ou suas primícias não diretamente vinculadas à profusão da materialidade e do simbolismo bibliográfico? O metaforismo do livro e a gramatização por trás dele, como visto, que também podem ser encarados como o metaforismo da tábula rasa, atravessam a justificativa de uma teoria do conhecimento na Antiguidade ("modernização" radical para o pensamento grego), a tradição gnosiológica romana, a justificativa de um neoplatonismo baseado na Sagrada Escritura, a "revelação" do livro da natureza e a filosofia da ciência Moderna, e chega até as linhagens de pensamento pós-estruturalista, como na posição derridiana. Entre os séculos XIX e XX, multiplicam-se os filósofos que buscam outros modos de pensar tendo como ponto de inflexão as complexas teias simbólicas do fazer bibliográfico e de seu refletir.

Em sua Arqueologia, por exemplo, Foucault (2010, p. 158) revela que todo método que propõe um modo de olhar que sugere seu procedimento reflexivo nada mais é do que uma certa "reescrita", ou, "na forma mantida da exterioridade, uma transformação regulada do que já foi escrito. Não é o retorno ao próprio segredo da origem; é já a descrição sistemática de um discurso-objeto". Trata-se de um modo de se atentar para os "regimes de materialidade".

O método de uma ciência que se propõe refletir o discurso é, em certa medida, sempre, um método bibliográfico: não por se ater necessariamente aos "impressos", mas por participar da vivência do mundo logológico cassiniano, o mundo que "diz o ser" e o "grafita", que reúne tantos e quantos gestos consigamos perceber na complexa intimidade entre homem e livro. Em outras palavras, toda a constituição do campo bibliográfico (em Peignot (1802a,b), campo bibliológico; em Otlet (1934), bibliológico, ou documentológico), remonta à "arqueologia" (em sentido geral, não foucaultiano) de um "ser" constituído e "perdido" na massa 
documental. Esta constituição, segundo a relação de Derrida (2004) com a condição do livro na filosofia moderna, remonta aGalileu, Descartes, Hume, Bonnet, Von Schubert, Novalis. Por sua vez, a arquê de Michel Foucault também se estabelece, se não dentro, em um penetrar nos rastros do labirinto bibliográfico:

[...] finalmente, o que se poderia chamar a 'biblioteca' ou o campo documentário, que compreende não somente os livros ou tratados, tradicionalmente reconhecidos como válidos, mas também o conjunto dos relatórios e observações publicadas e transmitidas, e ainda a massa de informações estatísticas (referente ao meio social, ao clima, às epidemias, à taxa de mortalidade, à frequência das doenças, aos focos de contágio, às doenças profissionais) que podem ser fornecidas ao médico pelas administrações, por outros médicos, por sociólogos, por geógrafos. Ainda aí, esses diversos 'lugares' do discurso médico foram profundamente modificados no século XIX: a importância do documento não deixa de crescer (diminuindo, proporcionalmente, a autoridade do livro ou da tradição). (FOUCAULT, 2010, p. $57-58)$

Como vimos, não só a Arqueologia foucaultiana se debruça sobre a simbologia e a materialidade simbólica do mundo do livro, como todo o projeto de Jacques Derrida de tentativa de construção de uma ciência do traço, da incisão, do talho inaugural, aqui se coloca. Por sua vez, a virada linguística da filosofia, por exemplo, atentada por Habermas (2004), é antes, ou também, ou co-incidente com a virada bibliográfica definitiva da filosofia: a filosofia da linguagem ou é a filosofia do livro, ou não é uma filosofia.

A modernidade, em minúscula, como impressão, a transformação de nossas relações no mundo sensível, tem no pensamento filosófico-bibliográfico uma linha de reflexão impressionante: filigrana mais resistente que um cabo de aço na duração de milênios, sob as revoluções das gramaticalizações, resulta de uma relação entre os pressupostos filosóficos da tábula rasa e sua "carnalização" (que pode significar também, se desejarmos, banalização, vulgarização, popularização) no espaço-tempo: afixada à memória artificial (mineral, animal, vegetal, eletrônica), a linguagem se faz verbo ordenador, traveste o conhecimento ou o concebe, conforme a perspectiva. Sem a prensa gutembergiana no século XV, é sabido, um conjunto de "modernizações" não seria possível, reduzindo substancialmente toda e qualquer imagem de uma certa Modernidade hoje estabelecida. $\mathrm{O}$ ato de imprimir, de incisar, de talhar, de grafitar, representa, no entanto, o "gesto moderno" (inovador) nas mais diferentes temporalidades, na medida em que suprime a virtualidade para multiplicá-la: a impressão é atual, mas abre uma miríade de potencialidades, sendo, ao mesmo tempo, máquina de virtualidades, ontem e hoje, se reconhecermos a revolução eletrônica (como outra revolução bibliográfica) no ethos contemporâneo, o modo de habitar o sensível extremamente enraizado nas práticas bibliográficas.

InCID: R. Ci. Inf. e Doc., Ribeirão Preto, v. 7, n. esp., p. 7-22, ago. 2016. 
Modernidade: uma impressão

\section{Referências}

ABBAGNANO, N. Dicionário de filosofia. 4. ed. São Paulo: Martins Fontes, 2000.

AUROUX, S. A revolução tecnológica da gramatização. Campinas: Unicamp, 2009.

A filosofia da linguagem. Campinas: Unicamp, 1998.

BURKE, P. Problemas causados por Gutenberg: a explosão da informação nos primórdios da Europa moderna. Estudos avançados, São Paulo, n. 44, v. 16, p. 173-185, jan./abr. 2002.

CASSIN, B. O Efeito sofístico. São Paulo: 34, 2005.

CURTIUS, E. R. Literatura européia e idade média latina. São Paulo: Hucitec, 1996

DEBRAY, R. Deus, um itinerário: material para a história do Eterno no Ocidente. São Paulo: Cia das Letras, 2004.

DERRIDA, J. Papel-máquina. São Paulo: Estação Liberdade, 2014. Gramatologia. São Paulo: Perspectiva, 2008.

FOUCAULT, M. Arqueologia do saber. Rio de Janeiro: Forense Universitária, 2010.

HABERMAS, J. Pensamento pós-metafísico: ensaios filosóficos. Coimbra: Almedina, 2004.

MELOT, M. Livro. Cotia: Ateliê Editorial, 2012.

NOLA, A. Livro. In.: ENCICLOPEDIA Einaudi. v. 12. Mythos $L$ Logos. Porto: Imprensa Nacional - Casa da Moeda, 2000. p. 215-242.

OTLET, P. Traité de documenatation: le livre sur le livre: théorie et pratique. Bruxelas: Editiones Mundaneum, 1934.

PEIGNOT, G. Dictionnaire raisonné de bibliologie. Paris: Chez Villier, 1802a. tomo I Dictionnaire raisonné de bibliologie. Paris: Chez Villier, 1802b. tomo II 